\title{
Overexpression of HGF Retards Disease Progression and Prolongs Life Span in a Transgenic Mouse Model of ALS
}

\author{
Woong Sun, ${ }^{*}$ Hiroshi Funakoshi, ${ }^{*}$ and Toshikazu Nakamura \\ Division of Molecular Regenerative Medicine, Course of Advanced Medicine, Osaka University Graduate School of \\ Medicine, B-7, Osaka 565-0871, Japan
}

\begin{abstract}
Amyotrophic lateral sclerosis (ALS) is a fatal neurodegenerative disease characterized by a progressive loss of motoneurons and degeneration of motor axons. We show that overexpression of hepatocyte growth factor (HGF) in the nervous system attenuates motoneuron death and axonal degeneration and prolongs the life span of transgenic mice overexpressing mutated $\mathrm{Cu}^{2+} / \mathrm{Zn}^{2+}$ superoxide dismutase 1. HGF prevented induction of caspase- 1 and inducible nitric oxide synthase (iNOS) in motoneurons and retained the levels of the glial-specific
\end{abstract}

Amyotrophic lateral sclerosis (ALS) is a progressive fatal disease involving loss of motoneurons and degeneration of motor axons. Approximately $5-10 \%$ of patients have familial ALS (FALS), and of those $\sim 15-25 \%$ carry a mutation(s) in the gene encoding $\mathrm{Cu}^{2+} / \mathrm{Zn}^{2+}$ superoxide dismutase (SOD1). Because transgenic mice with mutant SOD1 activity develop deficits found in both FALS and sporadic ALS, we used transgenic mice overexpressing mutated SOD1 ${ }^{\text {G93A }}$ (G93A mice) as a model for ALS (Gurney et al., 1994). Although motoneuronal degeneration is thought to be a primary event in disease progression and many treatment approaches have focused on either directly supporting the survival of motoneurons or preventing their death, astrocytic alterations are also apparent in ALS. For example, selective loss or reduction in activity of the glial-specific glutamate transporter [excitatory amino acid transporter 2 (EAAT2)/glutamate transporter 1 (GLT-1)] has been found in FALS and sporadic ALS patients and in the animal model of ALS (Rothstein et al., 1992, 1995; Bruijn et al., 1997); hence glial cells can also be important targets for ALS therapy. Indeed, introduction of neither neuron-specific nor astrocyte-specific mutant SOD1 is sufficient to present the ALS-like phenotype (Pramatarova et al., 2001); therefore a multipotential molecule capable of restoring the function of astrocytes and directly rescuing motoneurons would be ideal for the treatment of patients with ALS.

Hepatocyte growth factor (HGF) was first identified as a potent

Received Oct. 16, 2001; revised April 1, 2002; accepted May 2, 2002.

This work was supported in part by Research Grants from Center of Excellence to T.N. and the Ministry of Education, Science, Technology, Sports and Culture of Japan and the Ministry of Health and Welfare to T.N. and H.F. W.S. was a postdoctoral fellow from the Japan Society for Promotion of Science. We are grateful to Dr. P. Doherty for the pNSE-Ex vector and to Dr. C. F. Ibanez and M. Ohara for critical comments on this manuscript.

${ }^{*}$ W.S. and H.F. contributed equally to this work.

Correspondence should be addressed to Dr. Toshikazu Nakamura, Division of Molecular Regenerative Medicine, Course of Advanced Medicine, B-7, Osaka University Graduate School of Medicine, Osaka 565-0871, Japan. E-mail: nakamura@onbich.med.osaka-u.ac.jp.

W. Sun's present address: Department of Neurobiology and Anatomy, Wake Forest University School of Medicine, Winston-Salem, NC 27157.

Copyright $(\odot 2002$ Society for Neuroscience $0270-6474 / 02 / 226537-12 \$ 15.00 / 0$ glutamate transporter (excitatory amino acid transporter 2/glutamate transporter 1) in reactive astrocytes. We propose that HGF may be the first example of an endogenous growth factor that can alleviate the symptoms of ALS by direct neurotrophic activities on motoneurons and indirect activities on glial cells, presumably favoring a reduction in glutamatergic neurotoxicity.

Key words: HGF; c-Met; amyotrophic lateral sclerosis; caspase-1; EAAT2; motoneuron mitogen for mature hepatocytes and was molecularly cloned in 1989 (Nakamura et al., 1984, 1989). HGF prevents endotoxininduced lethal hepatic failure in mice with fulminant hepatitis via its anti-apoptotic activity, and HGF gene therapy is capable of improving the survival rate of rats with lethal liver cirrhosis (Kosai et al., 1999; Ueki et al., 1999). In addition to its role as a hepatotrophic factor, extensive expression and functional studies, including knock-out/knock-in mouse strategies, revealed HGF to be a novel neurotrophic factor (Matsumoto and Nakamura, 1997; Maina and Klein, 1999). This factor exerts neurotrophic activities in the hippocampus, cerebral cortex, midbrain dopaminergic, cerebellar granular, sensory, and motoneurons, and sympathetic neuroblasts (Honda et al., 1995; Maina and Klein, 1999). Furthermore, HGF is one of the most potent survival-promoting factors for motoneurons, comparable to glial cell line-derived neurotrophic factor (GDNF) in vitro (Ebens et al., 1996). Neurotrophic effects on embryonic spinal motoneurons during development and on adult motoneurons after axotomy of the hypoglossal nerve have been shown in vivo (Okura et al., 1999; Novak et al., 2000). Therefore, we explored the neuroprotective and molecular events related to the beneficial effects of HGF as a potent endogenous factor that may improve ALS. For this purpose, we crossed transgenic mice overexpressing HGF in a neuron-specific manner with transgenic mice overexpressing mutated SOD1 G93A (G93A mice). Here we report that introduction of the HGF gene into neurons of ALS-model mice attenuates motoneuronal degeneration and increases the life span of these mice. Our evidence suggests that HGF may act on both astrocytes and motoneurons.

\section{MATERIALS AND METHODS}

Transgenic mice. Full-length rat HGF cDNA tagged with the KT3 epitope was amplified by PCR and inserted into a pUC/SR $\alpha$-expression vector. Recombinant HGF-KT-3 showed similar potency to human recombinant HGF in Madin-Darby canine kidney scattering assays and in vitro survival assays of primary hippocampal neuronal cultures (data not shown). HGF-KT-3-poly(A) was excised from the vector and inserted downstream of the neuron-specific enolase promoter (NSE) promoter in the pNSE-Ex vector (kindly provided by Dr. P. Doherty, Department of Experimental Pathology, United Medical and Dental Schools, Guy's 
Hospital, London, UK). Transgenic mice were generated and analyzed for transgene integration, essentially as described, but with some modifications (Funakoshi et al., 1998). Briefly, a transgenic cassette was excised from the vector by SalI digestion, and DNA was injected into C57B6 embryos with a genetic background that matched that of G93A transgenic mice. Progenies of NSE-HGF transgenic mice were crossed with G93A transgenic mice [B6SJL-TgN(SOD1-G93A)1Gur ${ }^{\mathrm{dl}}$ ], purchased from Jackson Laboratory (Gurney et al., 1994), This mouse strain has fewer copy numbers of SOD-1 ${ }^{\mathrm{G} 93 \mathrm{~A}}$ and shows delayed onset and a longer life span, thus resembling findings in FALS patients. Each litter was housed in the same cage until the time of onset of the phenotypes. After the first sign of onset, animals were separated. Food and water were placed at the bottom of the cage allowing the animals ad libitum access to food and water. When an animal could not stand up within $30 \mathrm{sec}$, this time was noted as the time of death. Experiments were conducted in accordance with the guidelines of Osaka University Animal Ethical Committee.

RNase protection assay. RNase protection assays were performed as described (Funakoshi et al., 1993). A 326 bp fragment encompassing the $3^{\prime}$ end of HGF, KT-3, and part of poly(A) was inserted into a pGEM-T vector and used to generate antisense cRNA specific for HGF mRNA in the presence of $\alpha-\left[{ }^{32} \mathrm{P}\right] \mathrm{CTP}$. Exogenous HGF RNA gives a $326 \mathrm{bp}$ protected band, whereas endogenous HGF RNA gives a shorter protected band (251 bp), because it lacks the KT-3 and poly(A) sequences.

Astrocyte cell cultures. Primary astrocytes were cultured from cerebral cortex of postnatal day 2 G93A or wild-type littermates, as described (Naveilhan et al., 1996; H. Funakoshi and T. Nakamura, unpublished observations). Seven days after plating when cultures became confluent, cells were washed twice with PBS and treated with recombinant human HGF (Nakamura et al., 1989; Seki et al., 1990; Funakoshi et al., 2001) (30 $\mathrm{ng} / \mathrm{ml}$ ) for $3 \mathrm{~d}$. The purity of astrocytes usually exceeded $95 \%$ after $7 \mathrm{~d}$ in culture, as determined by double immunostaining with NSE/glial fibrillary acidic protein (GFAP).

$R T-P C R$. Quantitative competitive RT-PCR for the ventral horn of spinal cord was performed, as described (Sun et al., 2000).

Behavioral testing. Tests were administered to 15 animals of each genotype from six families. Footprints were collected by letting the mouse walk on a straight path after the hindpaw had been dipped in black ink. Stride was measured within the area showing regular walking. Examiners were unaware of the genotypes or ages of the mice.

Enzyme-linked immunosorbent assay. Levels of HGF in tissues or plasma were measured using an anti-rat HGF polyclonal antibody (Tokushu Meneki, Tokyo, Japan). The rat HGF ELISA system specifically detects rat and mouse HGF, with a similar affinity.

Immunoblotting analysis. Lumbar spinal cord lysates were prepared in RIPA buffer (150 mm NaCl, $1 \%$ NP-40, $0.5 \%$ deoxycholate, $0.1 \%$ SDS, $50 \mathrm{~mm}$ Tris, pH 8.0). Equal amounts of proteins of lysates $(50 \mu \mathrm{g})$ were resolved by SDS-PAGE, transferred to a polyvinylidene difluoride membrane, and immunoblotted. The primary antibodies used were as follows: anti-EAAT2 (Chemicon International, Temecula, CA), anti-GFAP (Sigma, St. Louis, MO), anti-human SOD (Sigma), anti-c-Met (Santa Cruz Biotechnology, Santa Cruz, CA), anti-inducible nitric oxide synthase (iNOS) (Sigma), anti-Bcl-xL/S (Santa Cruz), and anti-Bcl-2 (Santa Cruz). After incubation of membranes with HRP-coupled secondary antibodies, proteins were visualized by ECL (Amersham), and band intensities were measured using a Fluorochem image analyzer (IS-8000).

Histological and immunocytochemical analyses. Motoneuron counts were performed in spinal cords embedded in paraffin and serially sectioned $(14 \mu \mathrm{m})$ from L5 to L4. Numbers of motoneurons (within L4-L5) in the ventral horn were counted from 20 sections in every seventh section. We counted neurons densely stained with Cresyl violet with a clear nucleolus and in a defined area of the ventral horn. For immunohistochemistry, antibodies specific for c-Met (polyclonal) (Sun et al., 1999; Funakoshi and Nakamura, 2001), HGF (polyclonal) (Tokushu Meneki), human SOD (monoclonal) (Sigma), GFAP (monoclonal) (Sigma), $\beta$-tubulin ( $\beta$ III) (monoclonal) (Babco, Richmond, CA), and caspase-1 (polyclonal) (Santa Cruz), were applied to sections for 1-4 hr at room temperature or overnight at $4{ }^{\circ} \mathrm{C}$ after blocking with $5 \%$ goat serum and mouse IgG blocking reagents (M.O.M Kit, Vector Laboratories, Burlingame, CA). After washing in PBS, biotin- or fluorescencelabeled secondary antibodies were applied for $15 \mathrm{~min}$. Sections incubated with the biotinylated secondary antibody were subsequently washed and incubated with ABC solution (Vector) and developed with DAB. Fluorescence-immunostained sections were observed under the fluorescent microscope after counterstaining with Hoechst33342. Images were captured and digitized using a CCD camera (Hamamatsu), and the fluorescence level was measured using Adobe PhotoShop. The specificity of our antibody for c-Met was determined in an absorption test using an excess amount of immunized peptide [blocking peptide/m-Met (SP260)P, Santa Cruz] for immunostaining and Western blot analysis using anti-cMet antibody. The specificity of antibody for HGF was determined in an absorption test using recombinant rat HGF and in immunoprecipitation and subsequent Western blot analysis using anti-HGF antibody as described previously (Nakamura et al., 2000; Sun et al., 2000; Funakoshi and Nakamura, 2001). The staining specificity of the other antibodies was also assessed by (1) preadsorption of the primary antibody with excess peptide, (2) omission of the primary antibody, or (3) replacement of the primary antibody with normal rabbit IgG.

The L5 root was dissected and fixed overnight with $4 \%$ paraformaldehyde $/ 0.25 \%$ glutaraldehyde. After postfixing with osmium tetraoxide, roots were dehydrated and embedded in Epon812. Embedded roots were sectioned $(1 \mu \mathrm{m})$ and stained with toluidine blue, and the morphology was examined under a light microscope.

Statistical analysis. For all statistical analyses we used the Student's $t$ test using Statview software (SAS Institute, Cary, NC).

\section{RESULTS}

\section{Expression and regulation of c-Met/HGF receptor in the spinal cord of wild-type and mutant (G93A) transgenic mice}

To examine the role of HGF in ALS, we first determined whether the c-Met/HGF receptor was expressed and regulated in G93A mice. These mice have a low copy number of SOD-1 ${ }^{\mathrm{G} 93 \mathrm{~A}}$, thus resembling FALS patients. Immunohistochemical analysis revealed that, at 2 months of age, c-Met/HGF receptor-like immunoreactivity (c-Met-IR) was specifically localized in large motoneurons of G93A mice, similar to that of wild-type littermates (Fig. $1 A$ ). It is noteworthy that at 8 months of age c-Met-IR was found in surrounding astrocyte-like small cells, as well as in the remaining motoneurons at a slightly higher level in G93A mice. Double-immunostaining analysis of the spinal cord, using antiGFAP and anti-c-Met antibodies, revealed that c-Met-IR was localized in the remaining large neurons and small GFAPpositive reactive astrocytes (Fig. $1 A$ ). These results suggest that HGF can act on motoneurons during all stages of disease and on reactive astrocytes at the end stage. Quantification of the levels of expression of $c$-met and HGF RNAs in the ventral horn of the spinal cord where motoneurons are localized revealed increased expression levels during progression of ALS in G93A mice (Fig. $1 B)$. These results suggest the possibility that HGF is involved in retarding disease progression, most likely as an endogenous injury response factor.

\section{Generation and characterization of HGF- overexpressing transgenic mice}

To explore the neuroprotective effects of HGF on ALS, we first generated transgenic mice overexpressing rat HGF under the regulatory control of the NSE promoter (HGF mice). Of the 12 different tissues examined for exogenous HGF RNA expression, RNase protection assay (RPA) showed that only brain and spinal cord were positive (Fig. $2 A$ ). Serum levels of HGF in HGF mice were comparable to those of wild-type littermates (Fig. 2B). The levels of HGF protein progressively increased in the spinal cord postnatally only after completion of major differentiation of spinal cord neurons (Fig. 2C). We did not find differences in size, weight, gross morphology, or behavior between the nongenotyped HGF mice and their littermates. In the motor nervous system, no developmental changes in the number of motoneurons and astrocytes or muscle weight were observed (Figs. 2D, $3 A, B, E)$ as a result of the introduction of HGF. This demonstrates the successful introduction of HGF into the nervous 


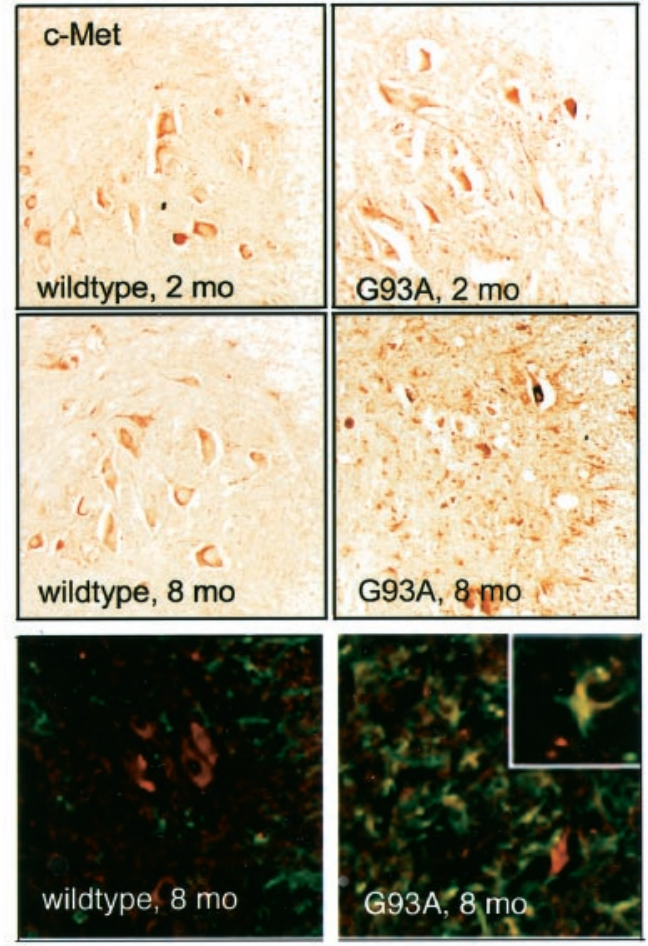

B
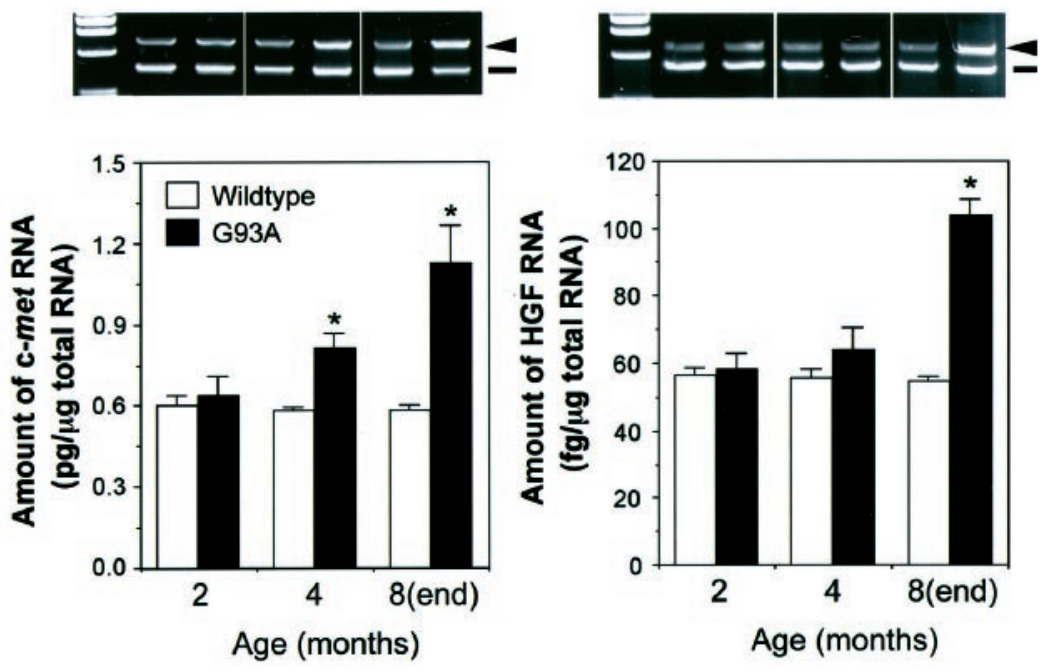

Figure 1. Expression and regulation of $\mathrm{HGF}$ and c-Met in G93A transgenic mice and wild-type littermates $(A-C)$ and characterization of transgenic mice overexpressing $\mathrm{HGF}$ $(D-F) . A$, Two-month-old wild-type or G93A mice showed c-Met-IR in the motoneurons. At 8 months of age (end stage of disease), c-Met-IR was observed in many cells of the ventral horn in G93A transgenic mice, whereas age-matched wild-type mice showed c-Met-IR similar to that seen in 2-month-old animals. The bottom panel shows a merged view of c-Met (red) and GFAP (green) in the spinal cord of 8-month-old mice. In wild-type mice, c-Met-IR was detected mainly in motoneurons, whereas G93A mice showed c-Met-IR in both remaining motoneurons and reactive astrocytes (inset shows magnified view). $B$, Induction of $c$-met and HGF mRNA wild-type littermates using a quantitative competitive RT-PCR ( $n=4$ in each group). Arrowheads indicate endogenous $c$-met or $\mathrm{HGF}$; large dashes indicate competitors. system without developmental modification of the motor nervous system.

\section{Neuroprotective effects of HGF in a transgenic murine model of ALS}

To determine the potential neuroprotective role(s) of HGF in ALS, we crossed hemizygous HGF mice with hemizygous G93A mice. This type of mating results in the generation of four groups of mice: (1) wild type, (2) HGF single transgenic (HGF), (3) G93A single transgenic (G93A), and (4) G93A and HGF double transgenic (G93A/HGF).

Single transgenic G93A mice began to lose motoneurons in the lumbar spinal cord at 6 months of age, and only $40 \%$ of motoneurons remained at 8 months of age, compared with wild-type or HGF single transgenic littermates (Fig. $3 A, B$ ). The remaining motoneurons in the G93A mice were atrophic. In contrast, double transgenic (G93A/HGF) mice retained a significantly larger number of spinal motoneurons with a healthier morphology than G93A mice at 7 and 8 months of age. Because in previous studies the survival-promoting activity of HGF on motoneurons was seen at both the cervical and lumbar levels in rats, but not at cervical levels in chicken embryos in vitro (Yamamoto et al., 1997; Novak et al., 2000), we also determined whether introduction of HGF 
A

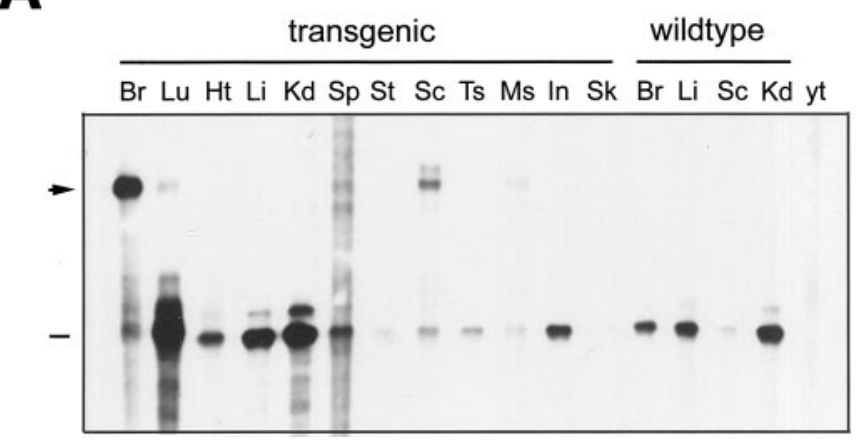

\section{C}

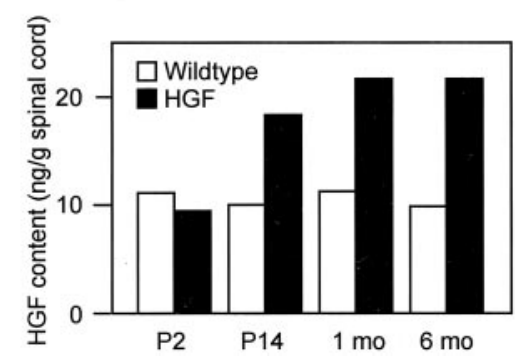

\section{D}

B
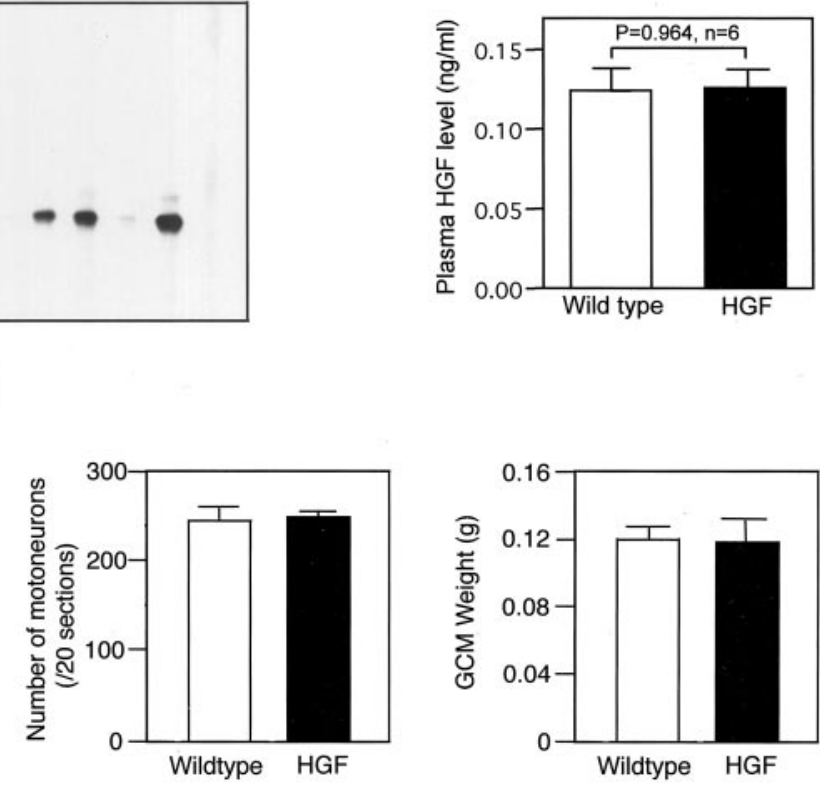

Figure 2. A, Tissue distribution of endogenous and introduced (exogenous) HGF in HGF transgenic mice compared with wild-type littermates. RPA revealed that exogenous HGF was introduced exclusively in neural tissues of HGF transgenic mice (arrow), whereas a similar level of endogenous HGF was expressed in tissues from HGF transgenic and wild-type mice (large dash). $B$, Plasma HGF levels, analyzed by ELISA, showed no difference between wild-type and HGF transgenic mice at 2 months of age $(n=6)$. $C$, In whole spinal cords of HGF transgenic mice, analyzed by ELISA, levels of HGF were increased from postnatal day 14 (P14). $D$, There was no difference in the number of spinal motoneurons and muscle weight between HGF transgenic and wild-type mice. $G C M$, Gastrocnemius muscle; $B r$, brain; $L u$, lung; $H t$, heart; $L i$, liver; $K d$, kidney; $S p$, spleen; $S t$, stomach; $S c$, spinal cord; $T s$, testes; $M s$, muscle; In, intestine; $S k$, skin; $Y t$, yeast tRNA.

would attenuate motoneuronal death at the cervical level. In 8-month-old G93A mice, 55\% of cervical motoneurons remained (Fig. $3 C$ ). The smaller number of motoneuronal deaths at the cervical level than at the lumbar level is characteristic of this mouse model. Because a significantly larger number of motoneurons $(87.8 \pm 2.4 \%)$ in double-transgenic mice remained at the cervical level (Fig. 3C), HGF was shown to be effective for both lumbar and cervical motoneurons.

We next assessed the effects of HGF on axonal degeneration. Degeneration of the ventral root was evident in 8-month-old G93A mice, whereas in double transgenic littermates degeneration of the ventral root was slight and morphology of the dorsal root was virtually normal (Fig. $3 D$ ). Therefore, HGF appears to exert neuroprotective effects against ALS-related neurotoxicity not only on motoneurons, but also on ventral and dorsal roots. Neuroprotective effects of HGF are also indicated from the delayed loss of weight of the gastrocnemius muscle (Fig. $3 E$ ).

\section{HGF improves motor performance, delays onset of paralysis, and prolongs life span of a transgenic murine model of ALS}

Next, we determined whether introduction of HGF would affect motor performance, onset of paralysis, and life span of G93A transgenic mice. Strides of animals were decreased in G93A mice from 6 months of age and decreased to one-fourth at 8 months of age, whereas strides were well conserved in G93A/HGF double transgenic mice until 8 months of age (Fig. $4 A$ ). Onset of paralysis was observed at the mean age of $243.8 \pm 4.7 \mathrm{~d}$ in the hemizygous G93A mice, whereas in G93A/HGF mice onset was significantly delayed to $271.9 \pm 5.6 \mathrm{~d}$ (median $=242 \pm 14$ vs $282.5 \pm 9.5 \mathrm{~d} ; p=$ 0.004 ) (Fig. 4B). The mean survival for G93A mice was $259.5 \pm$ $5.0 \mathrm{~d}$, and survival was also extended by $27.3 \mathrm{~d}$ to $286.8 \pm 6.5 \mathrm{~d}$ in $\mathrm{G} 93 \mathrm{~A} / \mathrm{HGF}$ mice $($ median $=259 \pm 11 \mathrm{~d}$ vs $294 \pm 14.5 \mathrm{~d} ; p=$ 0.003 ) (Fig. 4C). Levels of HGF protein in spinal cords in all four groups of mice during the progression of ALS are shown in Figure 5. The HGF level was approximately twofold higher at 2 and 6 months of age in HGF and G93A/HGF mice, demonstrating that even small amounts of HGF improved motor function, delayed onset of paralysis, and prolonged life span by 1 month.

We also examined the effects of HGF in G93A ${ }^{+/+}$homozygous mice, which show a more severe phenotype of ALS. Onset and mortality of G93A ${ }^{+/+}$mice was $137.8 \pm 2.4 \mathrm{~d}(n=4)$ and $147.5 \pm$ $5.7 \mathrm{~d}(n=4)$, respectively (Table 1$)$. In contrast, onset and mortality of the $\mathrm{G} 93 \mathrm{~A}^{+/+} / \mathrm{HGF}^{+/-}$mice were $161.5 \pm 3.4 \mathrm{~d}(n=$ $4)$ and $175.3 \pm 6.5 \mathrm{~d}(n=4)$, respectively (Table 1$)$. Therefore, in $\mathrm{G} 93 \mathrm{~A}^{+/+} / \mathrm{HGF}^{+/-}$mice, onset and life span were prolonged by $23.7 \mathrm{~d}(17.2 \%)$ and $27.8 \mathrm{~d}(18.8 \%)$, respectively.

Taken together, these results show that the introduction of the HGF gene into ALS neurons significantly extended the life span of and motor functions in a transgenic mouse model of ALS.

HGF does not modify the amount and aggregation of mutant SOD1 in the spinal cord of a transgenic murine model of ALS

To explore possible mechanisms of the HGF neuroprotective effects, we determined whether HGF would modify the initial and later events of ALS or the rate of disease progression without affecting specific events. Because aggregation of mutant SOD1 
A

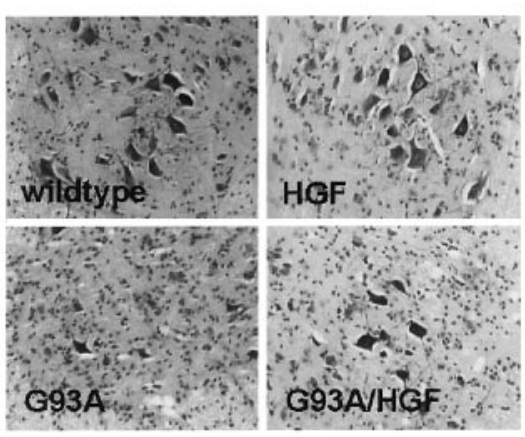

D
B

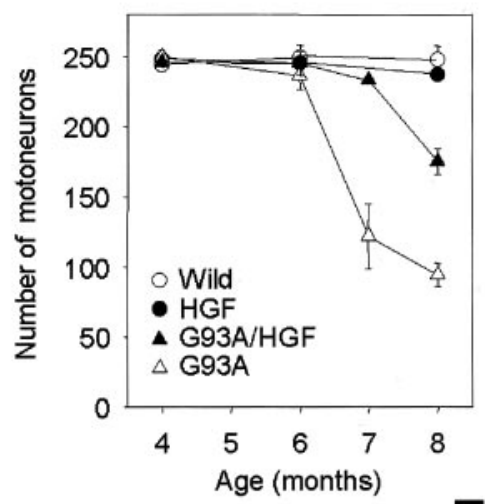

C

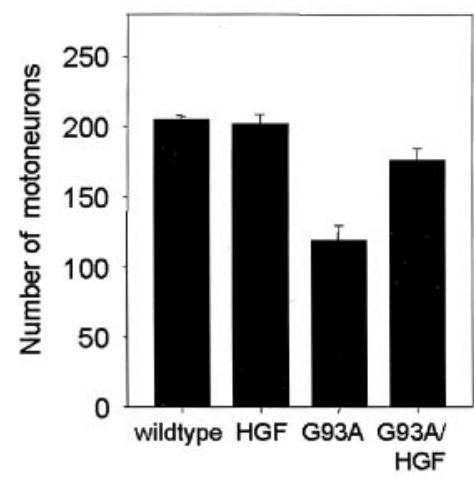

E
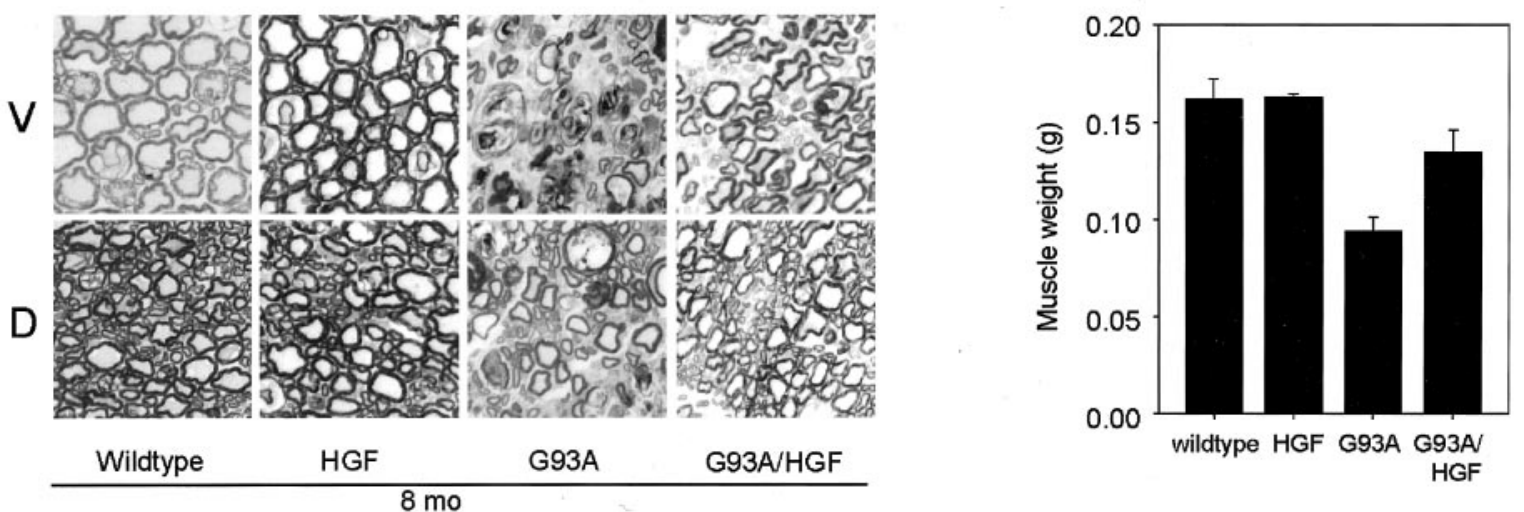

Figure 3. Protective effects of HGF against mutant SOD1 neurotoxicity. $A$, Cresyl violet-stained paraffin sections of the ventral horn of the lumbar spinal cord at the end stage of disease showed a markedly reduced number of motoneurons in G93A mice $(G 93 A)$ with an atrophic morphology, whereas double transgenic mice $(G 93 A / H G F)$ showed a much higher number of motoneurons with a healthy morphology. Wild-type and single transgenic HGF mice $(H G F)$ showed a similar number of healthy motoneurons. $B, C$, Quantitative graph showing an increase in the number of motoneurons in double transgenic mice at the lumbar level, compared with G93A mice ( $n=6$ in each group) and at the cervical level at 8 months of age ( $n=6$ in each group). $\bigcirc$, Wild type; $\bullet$, HGF single transgenic; $\Delta$, G93A; $\Delta$ G93A/HGF mice. $D$, Cross section $(1 \mu \mathrm{m})$ of ventral $(V$, top panel $)$ and dorsal $(D$, bottom panel $)$ roots at 8 months of age $(n=3$ in each group). The morphology of the ventral roots showed severe degeneration of large axons in G93A mice, compared with findings in wild-type or HGF mice. In double transgenic littermates, a greater number of large axons remained intact. The morphology of the dorsal roots showed moderate degeneration in G93A mice, whereas in double transgenic littermates the dorsal root was intact. Root morphologies were examined in at least three independent animals per group. $E$, Wet weight of the gastrocnemius muscle. Loss of muscle weight was slowed in G93A/HGF mice during the progression of ALS.

had been reported to be the earliest event in this animal model of ALS and SOD1, aggregation was observed in FALS patients (Bruijn et al., 1998). We first examined the aggregation of mutant SOD1 in our transgenic mice. Western blot analysis of spinal cord extracts detected mutant SOD1 in 2-month-old mice with a similar increase in amounts of mutant SOD1 in both G93A and G93A/HGF mice, with a similar time course (Fig. 4A). The aggregation of mutant SOD1 in the spinal cord of G93A mice seemed to be preferential in the ventral horn as early as 4 months, and the extent of aggregation was markedly increased at age 8 months (Fig. 6B). Similarly, aggregation of mutant SOD1 in double transgenic mice was evident at age 4 months and was slightly lower compared with G93A littermates at age 8 months (Fig. 6B). These results suggest that, in our model, HGF does not modify the origin of neurotoxicity and initial events of disease.

\section{The neuroprotective effect of HGF is independent of induction of the Bcl-2 family}

Because HGF induces Bcl-xL, a member of the Bcl-2 family, and blocks massive apoptosis of hepatocytes in the liver in fulminant hepatitis models (Kosai et al., 1999), we determined whether
HGF would exert effects via induction of the Bcl-2 family in G93A transgenic mice. Western blot analyses revealed that neither $\mathrm{Bcl}-\mathrm{xL}$ nor $\mathrm{Bcl}-2$ proteins were induced in the spinal cord of 8-months-old animals (Fig. 6C).

HGF attenuates induction of caspase-1 in spinal cords of a transgenic murine model of ALS

We then determined whether HGF modifies the induction of caspase-1, to address the question as to which stage of ALS can be modified by HGF. During the middle stages of ALS, caspase-1 is thought to play an important role in disease progression, because it is induced or activated in motoneurons of transgenic mice overexpressing mutated SOD1 (Pasinelli et al., 1998; Li et al., 2000), and introduction of a dominant negative inhibitor for caspase- 1 in G93A mice delayed mortality for $\sim 3$ weeks (Friedlander et al., 1997; Li et al., 2000). We did double-immunohistochemical analysis using antibodies against caspase-1 (red) and tubulin $\beta$ III ( green; marker of mature neurons) (Fig. 7A). Caspase-1-IR was under the detection limit in both wild-type and HGF littermates at all time points examined (data not shown). In 6-month-old G93A mice, introduced caspase-1-IR colocalized in large tubulin III- 
A

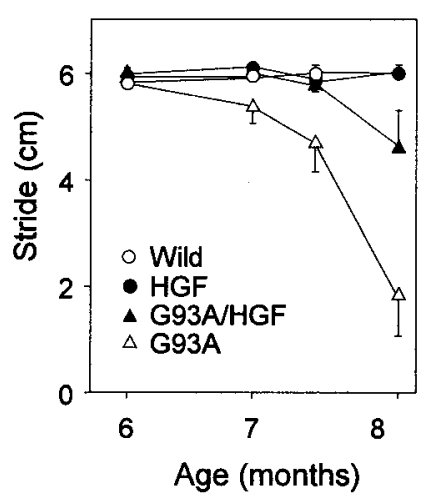

B

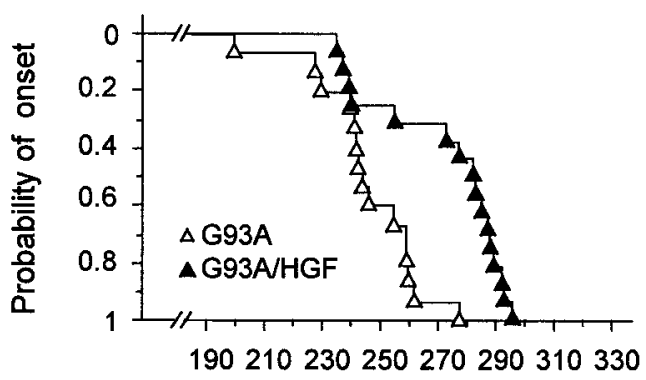

Age (days)

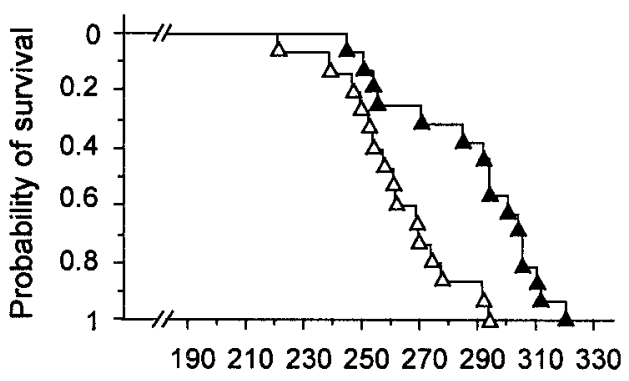

Age (days)

Figure 4. Improved motor performance, onset of paralysis, and mortality in G93A/HGF mice. $A$, Comparison of motor performance in wild-type, HGF, G93A, and G93A/HGF mice determined by stride; using a foot print test revealed that the stride was markedly decreased in G93A/HGF mice, whereas the stride was retained in G93A/HGF mice. $\bigcirc$, Wild type $(n=14) ; \boldsymbol{\bullet}$ HGF $(n=15) ; \boldsymbol{\Delta}, \mathrm{G} 93 \mathrm{~A}(n=16) ;$ and $\Delta, \mathrm{G} 93 \mathrm{~A} / \mathrm{HGF}$ mice $(n=16) . B$, Onset of paralysis, scored as the first observation of paralysis of bilateral limbs, was delayed in G93A/HGF mice compared with G93A mice. $\Delta$, G93A $(n=15) ; \boldsymbol{\Delta}$, G93A/HGF mice $(n=16)$. $C$, Probability of survival showed an extended life span in G93A/HGF mice compared with G93A mice.

immunostained cells, thus indicating the induction of caspase- 1 in motoneurons. The levels of caspase-1-IR in 8-month-old G93A mice were decreased, and only a faint caspase-1-IR was detected. In contrast to the G93A mice, 6-month-old double transgenic mice showed much lower levels of caspase-1-IR in large tubulin III-IR cells (Fig. 7A). Differences of the caspase-1-IR in motoneurons between G93A mice and G93A/HGF mice were $~ 2.5$ fold (Fig. $7 B$ ). At $7-8$ months of age, double transgenic mice

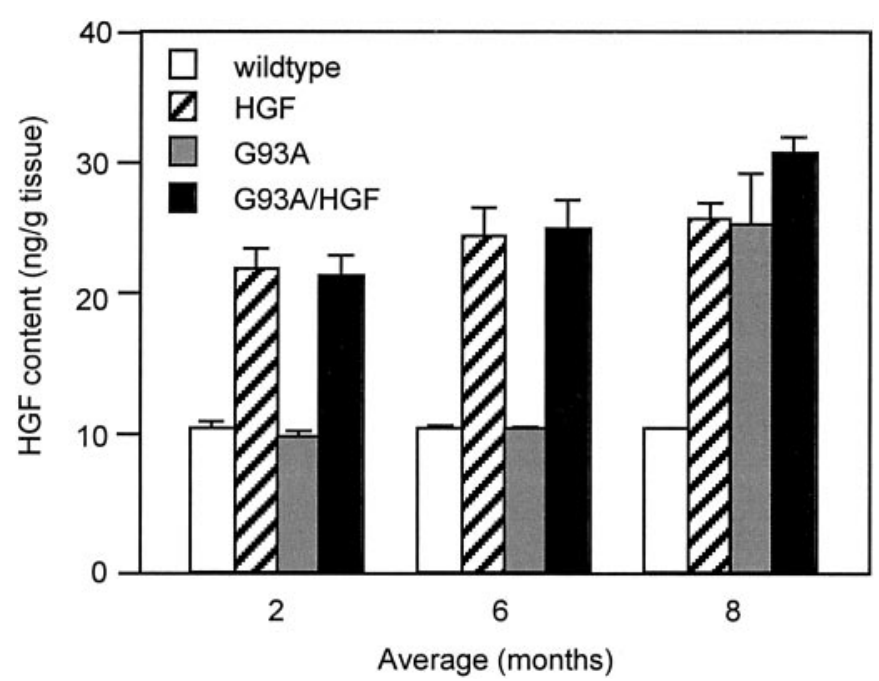

Figure 5. HGF protein levels in the spinal cords of wild-type, HGF, G93A, and G93A/HGF mice. Protein levels of HGF were determined by ELISA.

showed faint caspase-1-IR (data not shown). HGF apparently reduced the levels of caspase-1 induction in motoneurons at the middle stage of ALS. To clarify whether HGF could modify the levels of the active form of caspase-1, Western blot analysis of caspase-1 was performed using an antibody that recognizes both pro-caspase- 1 and the active fragment of caspase-1 (p20). This analysis revealed that production of the activated form of caspase-1 was induced in G93A mice, but its production was suppressed in G93A/HGF mice compared with that in G93A mice, suggesting that HGF supports survival of motoneurons partly because of the prevention of active caspase-1 induction, predominantly seen in motoneurons of G93A mice (Fig. 7C).

\section{Attenuation of the induction in levels of iNOS in a transgenic murine model of ALS}

Oxidative stress and induction of iNOS are thought to play an important role in the progression of ALS. Therefore, we addressed whether HGF would affect the levels of iNOS induced in motoneurons caused by the upregulation of nitric oxide and free radicals in ALS model mice. Immunohistochemical analysis of iNOS revealed that, consistent with previous reports, iNOS was induced in the motoneurons of G93A mice at 6 months of age, whereas this induction was attenuated in G93A/HGF mice, indi-

Table 1. Comparison of onset of paralysis, length, and mortality among G93A $^{+/-}$, G93A $^{+/-} / \mathbf{H G F}^{+/-}, \mathbf{G 9 3 A}^{+/+}$, and $\mathbf{G 9 3 A}^{+/+} / \mathrm{HGF}^{+/-}$mice

\begin{tabular}{lrcl} 
& $\mathrm{G} 93 \mathrm{~A}(+/-)$ & $\mathrm{G} 93 \mathrm{~A}(+/-) / \mathrm{HGF}(+/-)$ & $p$ value \\
\hline Onset & $243.8 \pm 4.7$ & $271.9 \pm 5.6$ & $0.004^{*}$ \\
Length & $15.7 \pm 1.6$ & $14.8 \pm 1.6$ & 0.686 \\
Mortality & $259.5 \pm 5.0$ & $286.8 \pm 6.5$ & $0.003^{*}$ \\
& $\mathrm{G} 93 \mathrm{~A}(+/+)$ & $\mathrm{G} 93 \mathrm{~A}(+/+) / \mathrm{HGF}(+/-)$ & $p$ value \\
\hline Onset & $137.8 \pm 2.4$ & $161.5 \pm 3.4$ & $0.007^{*}$ \\
Length & $12.0 \pm 2.0$ & $13.8 \pm 3.4$ & 0.457 \\
Mortality & $147.5 \pm 5.7$ & $175.3 \pm 6.5$ & $0.007^{*}$
\end{tabular}

*Statistical significance was evaluated by $t$ test.

Top panel, G93A $\mathrm{A}^{+/-}$mice; bottom panel, G93A ${ }^{+/+}$mice. Length is expressed as the duration (days) between onset and mortality. 


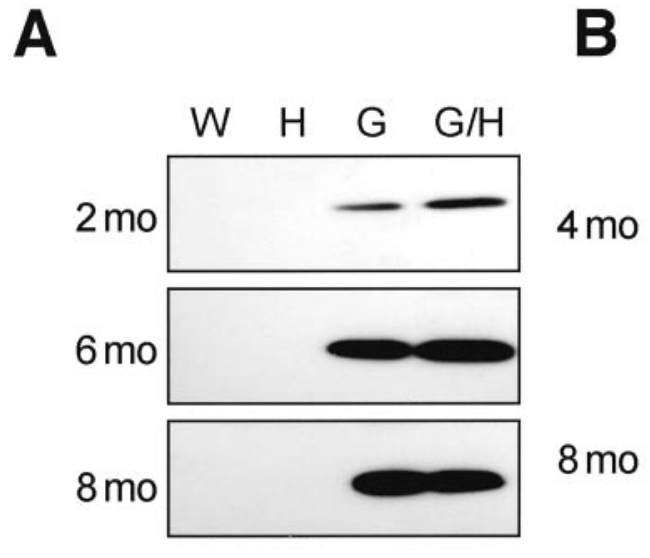

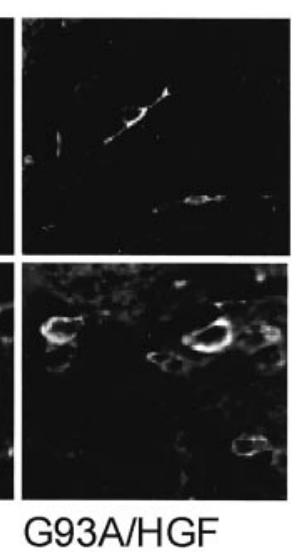
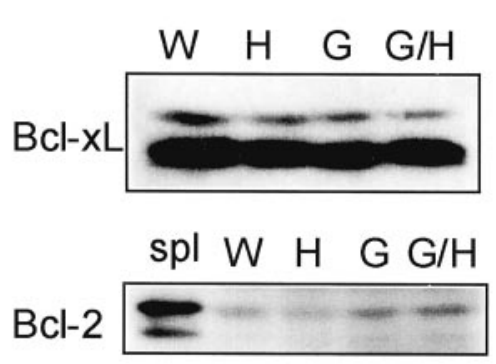

G93A

G93A/HGF

Figure 6. Modification of human SOD1, caspase-1, Bcl-xL, and Bcl-2 in the lumbar spinal cord during disease progression. $A$, Immunoblotting of human SOD1 in the lumbar spinal cord at 2, 6, and 8 months of age. The total amount of mutant SOD1 protein was not modified by overexpression of HGF at any time point examined. $W$, Wild type; $H, \mathrm{HGF} ; G, \mathrm{G} 93 \mathrm{~A} ; G / H$, G93A/HGF mice. $B$, Immunostaining of human SOD1 in the lumbar spinal cord at 4 months of age showed aggregation of SOD1 similar to that seen in G93A transgenic and G93A/HGF double transgenic mice $(n=3$ in each group). SOD1 aggregation was accumulated more densely in G93A or G93A/HGF mice at 8 months of age. A representative picture is shown of six sections at the lumbar level of each animal, and three mice per group were examined. $C$, Immunoblotting of Bcl-xL and Bcl-2 in the lumbar spinal cord at 8 months of age. No induction of Bcl-2 and Bcl-xL was evident in the spinal cord of G93A/HGF mice. $W$, Wild type; $H$, HGF; $G 93 A / H G F$, double transgenic mice; $s p l$, spleen as a positive control.

cating that HGF could also modify the levels of iNOS in motoneurons in addition to those of caspase-1 (Fig. 8).

\section{Reduction of gliosis and attenuation of the reduction in levels of EAAT2/GLT1 in a transgenic murine model of ALS}

Because we found c-Met-IR in reactive astrocytes in G93A mice at the end stage of disease (Fig. 1 $A$ ), we next focused on effects of HGF on astrocytes. In wild-type or HGF single transgenic mice, astrocytes were localized mainly in the white matter or cells surrounding the central canal and marginally in the ventral horn (Fig. 9A). Reactive astrocytes progressively proliferated in the ventral horn when motoneuronal death was not yet evident in 6-month-old G93A mice (Fig. 9A). In contrast, double transgenic littermates showed strikingly smaller numbers of reactive astrocytes in the ventral horn. Quantification of the relative intensity of GFAP-IR showed an $\sim 40$ and $60 \%$ decrease in the ventral horn, compared with findings in G93A mice at 6 and 8 months of age, respectively (Fig. 9B).

Because EAAT2 levels are reduced at the end stage of ALS, which is thought to be one of the critical events to increase glutamatergic neurotoxicity on motoneurons, we next determined whether EAAT2 levels were modified in G93A transgenic mice. At 8 months of age, EAAT2 levels in G93A mice were reduced to $40 \%$ compared with wild-type or HGF single transgenic littermates (Fig. 9C,D), which is consistent with reported data. In contrast, double transgenic mice showed even higher levels of EAAT2 $(140 \%)$ in the lumbar spinal cord compared with wildtype or HGF single transgenic littermates. To assess whether effects of HGF on EAAT2 levels are caused by a direct effect of HGF on astrocytes, we determined whether HGF treatment would modify levels of EAAT2 in primary cultured astrocytes. After $7 \mathrm{~d}$, only marginal levels of EAAT2 were detected in astrocytes from wild-type or G93A transgenic mice. In contrast, higher levels of EAAT2 were detected in astrocytes treated with HGF, suggesting that reduction in EAAT2 levels is caused by a direct activity of HGF on astrocytes through astrocytic foot processes attached to motoneurons (Fig. 9E,F). Taken together, these results indicate that single transgenic G93A mice overproduce nonfunctional astrocytes in terms of glutamate clearance, whereas double transgenic mice maintain more functional astrocytes.

\section{DISCUSSION}

We investigated whether gene transfer of HGF, a pleiotrophic cytokine with a highly potent neurotrophic activity for motoneurons, specifically to neurons of ALS model mice may play a role in disease retardation. Local and sustained delivery of the HGF gene into ALS neurons was achieved by generating transgenic mice overexpressing HGF in a neuron-specific manner (HGF mice) and by crossing HGF mice with transgenic mice expressing low copy number of mutant SOD1 ${ }^{\text {G93A }}$ (G93A mice), a mouse model of ALS. The HGF gene was introduced postnatally in neurons of HGF mice, and no differences could be seen in parameters of the motor nervous system examined, thus indicating comparable development of transgenic and control mice. In this system, exogenous HGF protein can be introduced into neurons at postnatal developmental stages of G93A mice. Only at later stages when reactive astrocytes proliferate and extend their foot processes to motoneurons can those astrocytes expressing c-Met at late stage of disease receive exogenous HGF protein produced in motoneurons.

Using this system, we provide the first evidence that HGF attenuates degeneration of both motoneuronal death and axonal degeneration, resulting in improved motor performance, delayed disease progression, and extension of the life span of transgenic mice overexpressing mutant SOD $1^{\mathrm{G} 93 \mathrm{~A}}$, via functions not only on motoneurons but also on astrocytes presumably through the foot processes facing motoneurons.

\section{Bifunctional role for HGF in delaying ALS progression}

Although the mechanisms of motoneuron-specific disease progression are not fully understood, regulation or accumulation of a series of molecules, such as SOD1, caspase-1, neurofilament, 
A

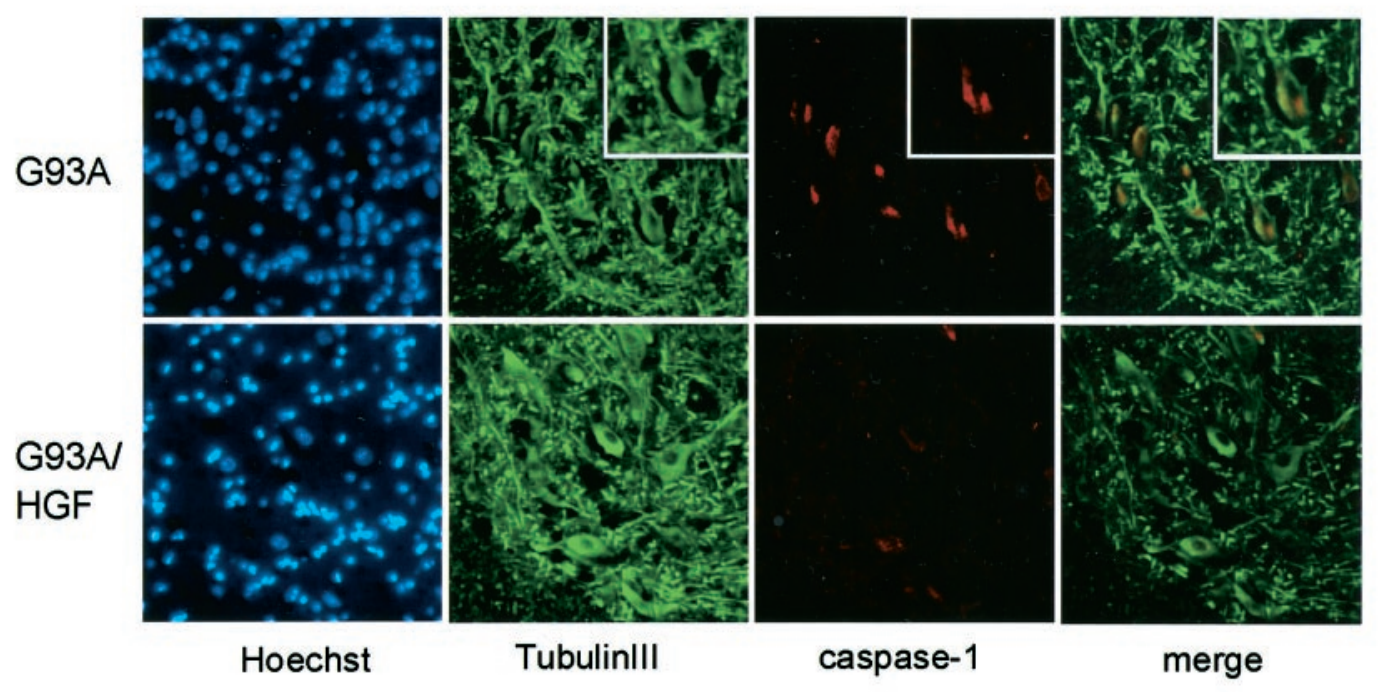

B

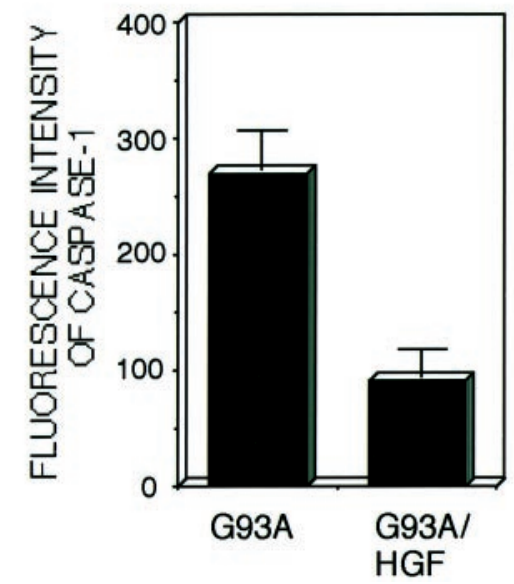

C

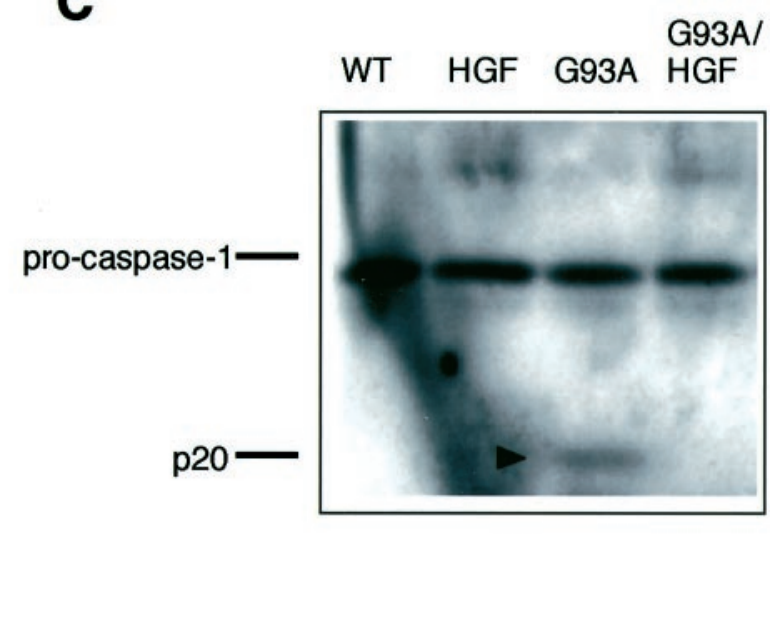

Figure 7. Attenuation of caspase-1 induction in double transgenic mice. A, Immunostaining of tubulin III ( green) and caspase-1 (red) in the lumbar spinal cord at 6 months of age $(n=3$ in each group). Caspase-1 was specifically induced in large tubulin III-positive neurons of G93A transgenic mice, whereas double transgenic mice showed much lower levels of caspase-1. Inset is magnified view. $B$, Comparison of the fluorescence intensity of caspase-1 in motoneurons. Fluorescence intensity of caspase-1-IR in each motoneuron was determined by image analysis using Photoshop after collecting the confocal image; average $\pm \mathrm{SE}$ of 40 motoneurons was expressed. $C$, Western blot analysis of caspase- 1 in the spinal cords of wild-type, HGF, G93A, and G93A/HGF mice.

and members of the Bcl-2 family, are thought to be involved in motoneuronal degeneration (Pasinelli et al., 1998; Strong, 1999; Vukosavic et al., 1999; Al-Chalabi and Leigh, 2000). One of the possible events affected by HGF is the regulation of the expression levels of members of the bcl-2 family, because we reported that HGF could induce Bcl-xL and attenuates massive cell death of hepatocytes of the fulminant hepatitis model in mice. Furthermore, it has been noted that overexpression of the anti-apoptotic oncoprotein $b c l-2$ in a neuron-specific manner prolongs the life span of ALS mice (Kostic et al., 1997), suggesting that HGF may prevent motoneuronal cell death via induction of the Bcl-2 family of proteins. Because we found the absence of induction of Bcl-2 and Bcl-xL at the end stage of ALS in G93A/HGF double transgenic mice, distinct mechanisms may play a role in the effects of HGF overexpression and Bcl-2 in ALS mice. We also showed in this study that aggregation of mutant SOD1, which occurred at a relatively early stage of the disease, was not modified. On the other hand, we found that a middle stage event (i.e., induction of caspase- 1 seen predominantly in motoneurons) was diminished in G93A/HGF double transgenic mice. Therefore it seems likely that attenuation of caspase- 1 induction in motoneurons may be responsible for HGF activity in preventing motoneuronal death at the middle stage of disease. This idea is supported by the evidence that intraventricular application of a dominant negative mutant of caspase-1 or a broad caspase inhibitor "zVAD-fmk" also attenuates motoneuronal death and prolongs the life span of ALS mice through a direct action on motoneurons (Friedlander et al., 1997; Li et al., 2000). In addition, attenuation of the induction of iNOS in motoneurons was evident by expression of HGF. Such direct neurotrophic activities of HGF on motoneurons might be of great importance in the attenuation of the progression of ALS. 


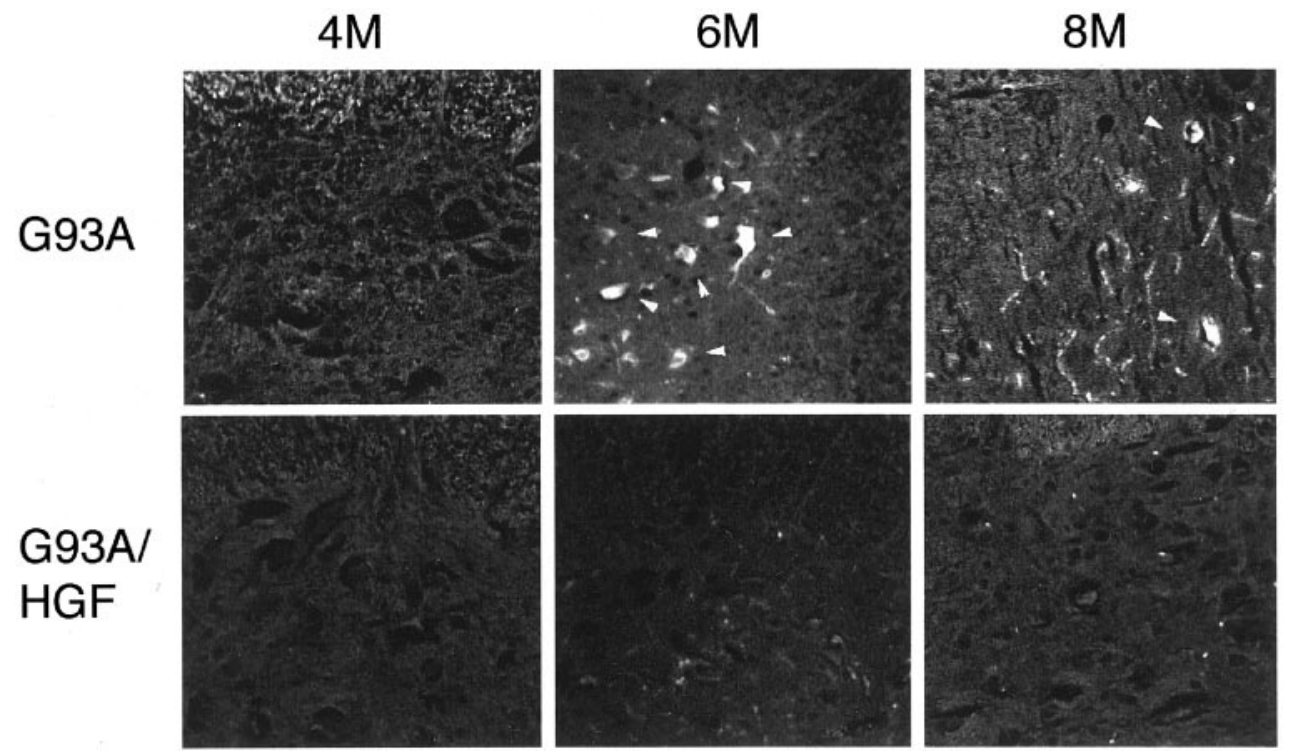

Figure 8. Attenuation of iNOS induction in double transgenic mice. Immunostaining was performed in the spinal cords of G93A and G93A/HGF mice at 4, 6, and 8 months of age. Arrowheads indicate iNOS- immunoreactive motoneurons.
It has been proposed that glutamate-mediated excitotoxicity contributes, at least in part, to the motoneuron-specific degeneration of ALS on the basis of findings that the level or activity of the glial-specific glutamate transporter (EAAT2/GLT-1), a major contributor to glutamate clearance, is reduced in ALS patients and model mice, especially at astrocytic foot processes (Rothstein et al., 1992, 1995; Bruijn et al., 1997). In addition, exposure of embryonic rat spinal dissociated cultures and coadministration of glutamate with a glutamate transporter inhibitor selectively injured motoneurons predominantly through NMDA and AMPA/ kainate receptors by activating $\mathrm{Ca}^{2+} /$ calmodulin-neuronal NOS but did not injure nonmotor neurons (Urushitani et al., 2001). Partial phenotypic improvement and prolongation of the life span of ALS model mice and patients by riluzole, a glutamate inhibitor, indicated the involvement of glutamatergic neurotoxicity in disease progression (Lacomblez et al., 1996; Gurney, 1997; Pongratz et al., 2000). Importantly, we found that HGF could retain or even increase the levels of EAAT2/GLT1, which suggests the improvement of glutamate clearance by HGF overexpression. This activity of HGF might be achieved via c-Met expressed in astrocytic foot processes directly attaching to neurons because c-Met was induced in reactive astrocytes at late stage of disease, and HGF increased the levels of EAAT2 in purified astrocytes from both G93A mice and their wild-type littermates. RNA processing of EAAT2 is reported in patients with ALS, as well as normal controls, patients with Alzheimer's disease, and patients with Lewy body dementia, neurodegenerative diseases in which motoneurons are unaffected (Lin et al., 1998; Honig et al., 2000). However, such processing does not occur for all RNA species. In addition, RNA processing of EAAT2 is not reported in G93A mice. Therefore, retaining the levels of or obtaining even higher levels of EAAT2 in G93A/HGF mice may be beneficial for reducing the glutamate neurotoxicities on motoneurons. An alternative possibility is that HGF acts on muscle cells, indirectly supporting the survival of motoneurons and preventing axonal degeneration or accelerating remodeling of the neuromuscular junction, because HGF promotes the proliferation of satellite cells in muscle (Miller et al., 2000). To clarify whether HGF acts directly on muscle, resulting in the beneficial effects on G93A mice, we should generate transgenic mice overexpressing HGF in a muscle-specific manner, generate double transgenic G93A/
muscle-HGF mice, and prove whether anterograde or retrograde transport of HGF between motoneurons and muscle is evident. In such cases, HGF could be more advantageous than other trophic factors. Another important issue is whether recombinant HGF prevents disease progression of G93A mice in a similar manner, but when we study the role of trophic factors on a transgenic mouse model of ALS, we may need to consider the delivery approach and prove that the trophic factor is effectively delivered into motoneurons. In some previously reported cases (Heads et al., 1991), sensory neurons in addition to motoneurons were affected at the late stage of the disease, supporting the concept that effects of glutamate differ with types of cells, which reflects the possibility of sensory modification in ALS. We also found axonal degeneration of sensory neurons at the late stage of disease in rare cases of G93A mice. HGF shows a neurotrophic activity in sensory neurons (Maina and Klein, 1999; Funakoshi and Nakamura, 2001), and it should be noted that HGF efficiently prevented sensory degeneration, which also suggests a role for HGF in the ALS sensory system.

These findings indicate that HGF might attenuate both survival and axonal degeneration of motoneurons and retard ALS disease progression by modulating at least two independent mechanisms: (1) attenuation of caspase-1 induction in motoneurons and (2) retention of the levels of EAAT2 in astrocytes, which could contribute to selective motoneuronal degeneration of ALS by affecting the middle-late stage events of ALS pathology, a common pathway for both FALS and sporadic ALS. Therefore, post-diagnostic HGF therapy can be considered not only for mutant SOD1-related FALS, but also for ALS in general. We are also currently examining the possibility that improved delivery of HGF may further enhance its effect at later stages of ALS.

\section{Neurotrophic factors in motoneuron diseases}

Molecules with neurotrophic activities have long been thought to be beneficial agents for the treatment of neurodegenerative disorders such as ALS and Alzheimer's and Parkinson's diseases, not only because of survival-promoting activity but also because of their neurite-promoting activity, which possibly assists in reorganizing neural networks (Hoffer and Olson, 1997; Connor and Dragunow, 1998; Kordower et al., 2000). Among neurotrophic factors, a combination of ciliary neurotrophic factor (CNTF) and 
A
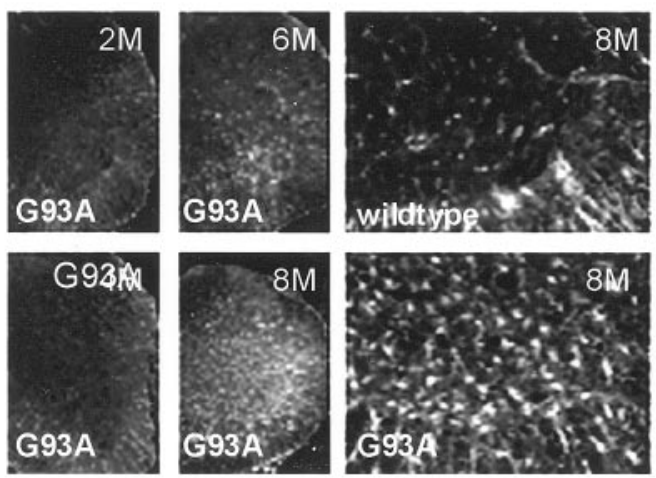
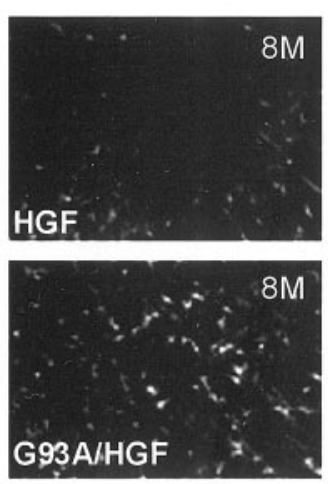

B

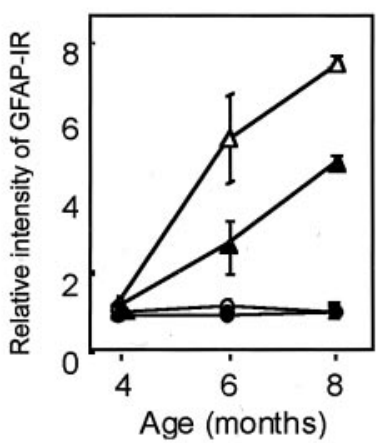

C

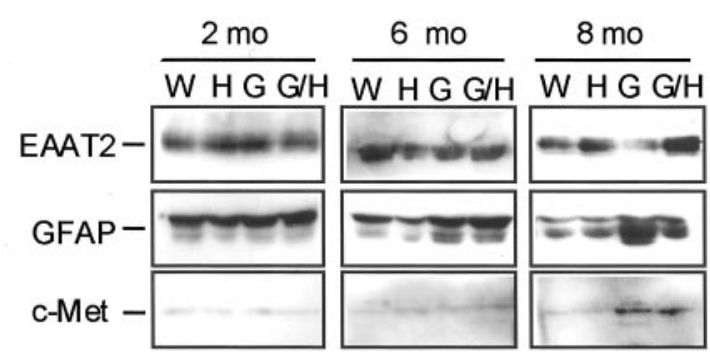

D

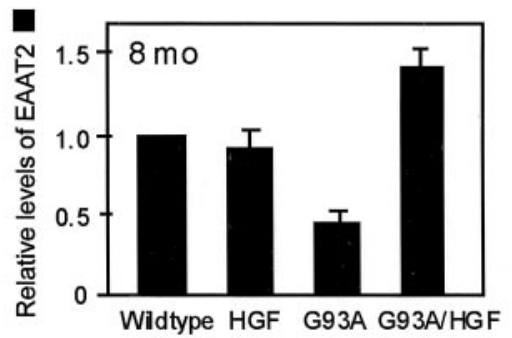

$\mathrm{E}$

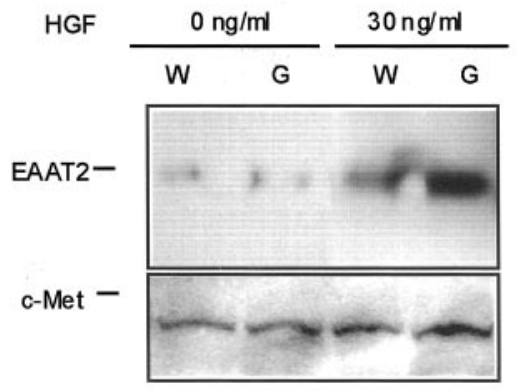

$\mathrm{F}$

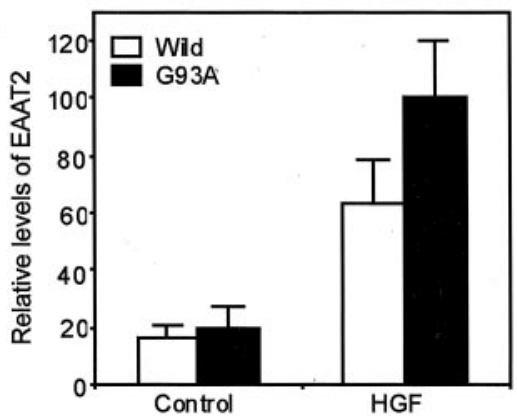

Figure 9. Attenuation of astrocytosis and downregulation of EAAT2 in double transgenic mice. $A$, Immunohistochemical analysis of GFAP in the ventral horn of the lumbar spinal cord at 8 months of age revealed that, in contrast to the marked proliferation of astrocytes in G93A mice, double transgenic mice showed fewer astrocytes in the ventral horn, whereas wild-type and HGF transgenic mice showed only a small number of astrocytes. $B$, Quantitative values of GFAP immunoreactivities in different mice. Relative intensity of GFAP-IR in wild type (O), HGF single transgenic $(\bullet)$, G93A $(\Delta)$, and double transgenic $(\mathbf{\Delta})(n=3$ in each group). $C$, Immunoblotting of EAAT2, GFAP, and c-Met in the spinal cord at 2, 6, and 8 months of age shows induction of GFAP from 6 months of age in both G93A and G93A/HGF mice. EAAT2 was downregulated in G93A mice and c-Met was upregulated in G93A and G93A/HGF mice specifically at 8 months of age. The total level of EAAT2 was maintained in G93A/HGF mice at 8 months of age. $D$, Relative levels of EAAT2 at 8 months of age $(n=4$ in each group). $E$, Immunoblotting of EAAT2 and c-Met in primary astrocytes. HGF treatment resulted in upregulation of EAAT2 in primary astrocytes from both wild-type and G93A mice. $F$, Quantitative results are shown $(n=3$ in each group).

brain-derived neurotrophic factor or CNTF and neurotrophin-3 are therapeutics for motoneuron diseases, as determined in model mice such as pmn or wobbler mice, respectively (Mitsumoto et al., 1994; Haase et al., 1997). In these models, combinations of neurotrophic factors slowed both motoneuronal death and axonal degeneration (Mitsumoto et al., 1994; Haase et al., 1997). GDNF has been shown to promote survival of motoneurons of G93A mice in vitro (Derby et al., 2000). In contrast to CNTF, GDNF significantly reduced the loss of facial motoneurons by $50 \%$, a number similar to what was observed when CNTF was administered to the pmn mice. Counts of myelinated axons revealed that GDNF-secreting cells had no effect on axonal degeneration and did not increase the lifespan of $\mathrm{pmn} / \mathrm{pmn}$ mice (Sagot et al., 1996). Despite its potential role in rescuing motoneuron cell bodies, it was suggested that the ability of GDNF to prevent nerve degeneration might be restricted to cotreatment with other factors that act on nerve processes (Sagot et al., 1996). Use of other neurotrophic factors, such as neurotrophin-4, has also been considered for ALS treatment because it promotes survival, neurite extension, and sprouting of motoneurons in an activity-dependent manner (Funakoshi et al., 1995). Although the potential benefits of using these neurotrophic factors in these ALS models are evident, it is also apparent that a combination of these neurotrophic factors is necessary. The mechanism(s) by which neurotrophic factors contribute to the survival and axonal regeneration of motoneurons is not fully understood, yet it is possible that these neurotrophic factors may function directly via their cognate receptors expressed on 
motoneurons, because their receptors are present in motoneuron and direct neurotrophic activity on motoneurons has been shown in vitro. Evidence of beneficial actions of these factors on glial cells is not evident.

In summary, because HGF acts on both survival and axonal regeneration of motoneurons and astrocytes, we propose that HGF is the first example of an endogenous cytokine that plays a dual role in ALS. This could take place through direct neurotrophic activities on motoneurons and indirect modification of glutamate neurotoxicity in motoneurons by maintaining appropriate levels of glutamate transporters in astrocytes. These functions of HGF raise the possibility for a therapeutic use of this factor in ALS and related disorders.

\section{REFERENCES}

Al-Chalabi A, Leigh PN (2000) Recent advances in amyotrophic lateral sclerosis. Curr Opin Neurol 13:397-405.

Bruijn LI, Becher MW, Lee MK, Anderson KL, Jenkins NA, Copeland NG, Sisodia SS, Rothstein JD, Borchelt DR, Price DL, Cleveland DW (1997) ALS-linked SOD1 mutant G85R mediates damage to astrocytes and promotes rapidly progressive disease with SOD1-containing inclusions. Neuron 18:327-338.

Bruijn LI, Houseweart MK, Kato S, Anderson KL, Anderson SD, Ohama E, Reaume AG, Scott RW, Cleveland DW (1998) Aggregation and motor neuron toxicity of an ALS-linked SOD1 mutant independent from wild-type SOD1. Science 281:1851-1854.

Connor B, Dragunow M (1998) The role of neuronal growth factors in neurodegenerative disorders of the human brain. Brain Res Brain Res Rev 27:1-39.

Derby ML, Giuliano R, Figlewicz DA, Bohn MC (2000) GDNF is trophic for mouse motoneurons that express a mutant superoxide dismutase (SOD-1) gene. Amyotroph Lateral Scler Other Motor Neuron Disord 1:113-122.

Ebens A, Brose K, Leonardo ED, Hanson Jr MG, Bladt F, Birchmeier C, Barres BA, Tessier-Lavigne M (1996) Hepatocyte growth factor/scatter factor is an axonal chemoattractant and a neurotrophic factor for spinal motor neurons. Neuron 17:1157-1172.

Friedlander RM, Brown RH, Gagliardini V, Wang J, Yuan J (1997) Inhibition of ICE slows ALS in mice. Nature 388:31.

Funakoshi H, Nakamura T (2001) Identification of HGF-like protein as a novel neurotrophic factor for avian dorsal root ganglion sensory neurons. Biochem Biophys Res Commun 283:606-612.

Funakoshi H, Frisen J, Barbany G, Timmusk T, Zachrisson O, Verge VM, Persson H (1993) Differential expression of mRNAs for neurotrophins and their receptors after axotomy of the sciatic nerve. J Cell Biol 123:455-465.

Funakoshi H, Belluardo N, Arenas E, Yamamoto Y, Casabona A, Persson H, Ibanez CF (1995) Muscle-derived neurotrophin-4 as an activity-dependent trophic signal for adult motor neurons. Science 268:1495-1499.

Funakoshi H, Risling M, Carlstedt T, Lendahl U, Timmusk T, Metsis M, Yamamoto Y, Ibanez CF (1998) Targeted expression of a multifunctional chimeric neurotrophin in the lesioned sciatic nerve accelerates regeneration of sensory and motor axons. Proc Natl Acad Sci USA 95:5269-5274.

Gurney ME (1997) The use of transgenic mouse models of amyotrophic lateral sclerosis in preclinical drug studies. J Neurol Sci 152:S67-73.

Gurney ME, Pu H, Chiu AY, Dal Canto MC, Polchow CY, Alexander DD, Caliendo J, Hentati A, Kwon YW, Deng HX (1994) Motor neuron degeneration in mice that express a human $\mathrm{Cu}, \mathrm{Zn}$ superoxide dismutase mutation. Science 264:1772-1775.

Haase G, Kennel P, Pettmann B, Vigne E, Akli S, Revah F, Schmalbruch H, Kahn A (1997) Gene therapy of murine motor neuron disease using adenoviral vectors for neurotrophic factors. Nat Med 3:429-436.

Heads T, Pollock M, Robertson A, Sutherland WH, Allpress S (1991) Sensory nerve pathology in amyotrophic lateral sclerosis. Acta Neuropathol (Berl) 82:316-320.

Hoffer B, Olson L (1997) Treatment strategies for neurodegenerative diseases based on trophic factors and cell transplantation techniques. J Neural Transm [Suppl] 49:1-10.

Honda S, Kagoshima M, Wanaka A, Tohyama M, Matsumoto K, Nakamura T (1995) Localization and functional coupling of HGF and c-Met/HGF receptor in rat brain: implication as neurotrophic factor. Brain Res Mol Brain Res 32:197-210.
Honig LS, Chambliss DD, Bigio EH, Carroll SL, Elliott JL (2000) Glutamate transporter EAAT2 splice variants occur not only in ALS, but also in AD and controls. Neurology 55:1082-1088.

Kordower JH, Emborg ME, Bloch J, Ma SY, Chu Y, Leventhal L, McBride J, Chen EY, Palfi S, Roitberg BZ, Brown WD, Holden JE, Pyzalski R, Taylor MD, Carvey P, Ling Z, Trono D, Hantraye P, Deglon N, Aebischer P (2000) Neurodegeneration prevented by lentiviral vector delivery of GDNF in primate models of Parkinson's disease. Science 290:767-773.

Kosai K, Matsumoto K, Funakoshi H, Nakamura T (1999) Hepatocyte growth factor prevents endotoxin-induced lethal hepatic failure in mice. Hepatology 30:151-159.

Kostic V, Jackson-Lewis V, de Bilbao F, Dubois-Dauphin M, Przedborski S (1997) Bcl-2: prolonging life in a transgenic mouse model of familial amyotrophic lateral sclerosis. Science 277:559-562.

Lacomblez L, Bensimon G, Leigh PN, Guillet P, Meininger V (1996) Dose-ranging study of riluzole in amyotrophic lateral sclerosis. Amyotrophic lateral sclerosis/riluzole study group II. Lancet 347:1425-1431.

Li M, Ona VO, Guegan C, Chen M, Jackson-Lewis V, Andrews LJ Olszewski AJ, Stieg PE, Lee JP, Przedborski S, Friedlander RM (2000) Functional role of caspase-1 and caspase-3 in an ALS transgenic mouse model. Science 288:335-339.

Lin CL, Bristol LA, Jin L, Dykes-Hoberg M, Crawford T, Clawson L, Rothstein JD (1998) Aberrant RNA processing in a neurodegenerative disease: the cause for absent EAAT2, a glutamate transporter, in amyotrophic lateral sclerosis. Neuron 20:589-602.

Maina F, Klein R (1999) Hepatocyte growth factor, a versatile signal for developing neurons. Nat Neurosci 2:213-217.

Matsumoto K, Nakamura T (1997) HGF: its organotrophic role and therapeutic potential. Ciba Found Symp 212:198-211.

Miller KJ, Thaloor D, Matteson S, Pavlath GK (2000) Hepatocyte growth factor affects satellite cell activation and differentiation in regenerating skeletal muscle. Am J Physiol Cell Physiol 278: C174-181.

Mitsumoto H, Ikeda K, Klinkosz B, Cedarbaum JM, Wong V, Lindsay RM (1994) Arrest of motor neuron disease in wobbler mice cotreated with CNTF and BDNF. Science 265:1107-1110.

Nakamura T, Nawa K, Ichihara A (1984) Partial purification and characterization of hepatocyte growth factor from serum of hepatectomized rats. Biochem Biophys Res Commun 122:1450-1459.

Nakamura T, Nishizawa T, Hagiya M, Seki T, Shimonishi M, Sugimura A, Tashiro K, Shimizu S (1989) Molecular cloning and expression of human hepatocyte growth factor. Nature 342:440-443.

Nakamura T, Mizuno S. Matsumoto K, Sawa Y, Matsuda H, Nakamura $\mathrm{T}$ (2000) Myocardial protection from ischemia/reperfusion injury by endogenous and exogenous HGF. J Clin Invest 106:1511-1519.

Naveilhan P, Neveu I, Baudet C, Funakoshi H, Wion D, Brachet P, Metsis M (1996) 1,25-Dihydroxyvitamin D3 regulates the expression of the low-affinity neurotrophin receptor. Brain Res Mol Brain Res 41:259-268.

Novak KD, Prevette D, Wang S, Gould TW, Oppenheim RW (2000) Hepatocyte growth factor/scatter factor is a neurotrophic survival factor for lumbar but not for other somatic motoneurons in the chick embryo. J Neurosci 20:326-337.

Okura Y, Arimoto H, Tanuma N, Matsumoto K, Nakamura T, Yamashima T, Miyazawa T, Matsumoto Y (1999) Analysis of neurotrophic effects of hepatocyte growth factor in the adult hypoglossal nerve axotomy model. Eur J Neurosci 11:4139-4144.

Pasinelli P, Borchelt DR, Houseweart MK, Cleveland DW, Brown Jr RH (1998) Caspase-1 is activated in neural cells and tissue with amyotrophic lateral sclerosis-associated mutations in copper-zinc superoxide dismutase. Proc Natl Acad Sci USA 95:15763-15768.

Pongratz D, Neundorfer B, Fischer W (2000) German open label trial of riluzole $50 \mathrm{mg}$ b.i.d. in treatment of amyotrophic lateral sclerosis (ALS). J Neurol Sci 180:82-85.

Pramatarova A, Laganiere J, Roussel J, Brisebois K, Rouleau GA, Andreassen OA, Jenkins BG, Dedeoglu A, Ferrante KL, Bogdanov MB, Kaddurah-Daouk R, Beal MF (2001) Neuron-specific expression of mutant superoxide dismutase 1 in transgenic mice does not lead to motor impairment. J Neurosci 21:3369-3374.

Rothstein JD, Martin LJ, Kuncl RW (1992) Decreased glutamate transport by the brain and spinal cord in amyotrophic lateral sclerosis. N Engl J Med 326:1464-1468.

Rothstein JD, Van Kammen M, Levey AI, Martin LJ, Kuncl RW (1995) Selective loss of glial glutamate transporter GLT-1 in amyotrophic lateral sclerosis. Ann Neurol 38:73-84.

Sagot Y, Tan SA, Hammang JP, Aebischer P, Kato AC (1996) GDNF slows loss of motoneurons but not axonal degeneration or premature death of $\mathrm{pmn} / \mathrm{pmn}$ mice. J Neurosci 16:2335-2341.

Seki T, Ihara I, Sugimura A, Shimonishi M, Nishizawa T, Asami O, Hagiya M, Nakamura T, Shimizu S (1990) Isolation and expression of cDNA for different forms of hepatocyte growth factor from human leukocyte. Biochem Biophys Res Commun 172:321-327. 
Strong MJ (1999) Neurofilament metabolism in sporadic amyotrophic lateral sclerosis. J Neurol Sci 169:170-177.

Sun W, Funakoshi H, Nakamura T (1999) Differential expression of hepatocyte growth factor and its receptor, c-Met, in the rat retina during development. Brain Res 851:46-53.

Sun W, Funakoshi H, Matsumoto K, Nakamura T (2000) A sensitive quantification method for evaluating the level of hepatocyte growth factor and c-met/HGF receptor mRNAs in the nervous system using competitive RT-PCR. Brain Res Brain Res Protoc 5:190-197.

Ueki T, Kaneda Y, Tsutsui H, Nakanishi K, Sawa Y, Morishita R, Matsumoto K, Nakamura T, Takahashi H, Okamoto E, Fujimoto J (1999) Hepatocyte growth factor gene therapy of liver cirrhosis in rats. Nat Med 5:226-230.
Urushitani M, Nakamizo T, Inoue R, Sawada H, Kihara T, Honda K, Akaike A, Shimohama S (2001) $N$-methyl-D-aspartate receptormediated mitochondrial $\mathrm{Ca}(2+)$ overload in acute excitotoxic motor neuron death: a mechanism distinct from chronic neurotoxicity after $\mathrm{Ca}(2+)$ influx. J Neurosci Res 63:377-387.

Vukosavic S, Dubois-Dauphin M, Romero N, Przedborski S (1999) Bax and Bcl-2 interaction in a transgenic mouse model of familial amyotrophic lateral sclerosis. J Neurochem 73:2460-2468.

Yamamoto Y, Livet J, Pollock RA, Garces A, Arce V, deLapeyriere O, Henderson CE (1997) Hepatocyte growth factor (HGF/SF) is a muscle-derived survival factor for a subpopulation of embryonic motoneurons. Development 124:2903-2913. 